\title{
Experimental study on irregular wave-induced pore-water pressures in a porous seabed around a mono-pile
}

\author{
Qibo Zhang ${ }^{1}$, Hualing Zhai ${ }^{2}$, Pandi Wang ${ }^{2}$, Shaohua Wang ${ }^{2}$, Lunliang \\ Duan $^{2}$, Linya Chen ${ }^{2}$, Yifei Liu ${ }^{2}$, Dong-Sheng Jeng ${ }^{3, \#}$ \\ 1 School of Port, Coastal and Offshore Engineering, Hohai University, Nanjing, 210098, \\ China \\ ${ }^{2}$ Department of Bridge Engineering, School of Civil Engineering, Southwest Jiaotong \\ University, Chengdu, 610031, China \\ 3 School of Engineering and Built Environment, Griffith University Gold Coast Campus, \\ Queensland, QLD 4222, Australia \\ \# Corresponding author. Email: d.jeng@griffith.edu.au
}

\begin{abstract}
In this study, a series of physical model tests were carried out in a wave flume to study the pore pressures around a mono-pile under irregular waves. The mono-pile was installed to the position of $0.6 \mathrm{~m}$ below the seabed surface. The main purpose of this study is to analyze the distribution of pore-water pressure around and beneath the mono-pile under irregular waves. Five different wave spectra were used in the tests. The experimental results conclude that: (1) the pore-water pressure around the pile increases as the increase of significant wave height and period; (2) the maximum pore-water pressure decreases as the increase of seabed depth $(z)$, this trend is significant near the seabed surface $(z \geq-0.3 \mathrm{~m})$, and the influence is not obvious for the region below $0.3 \mathrm{~m}$; (3) at the depth of $0.15 \mathrm{~m}$ below the seabed surface $(z=-0.15 \mathrm{~m})$, the maximum pore pressure occurs in front of the pile, and at the depth of $0.1 \mathrm{~m}$ below the bottom of the pile $(z=-0.7 \mathrm{~m})$, the maximum pore-water pressure occurs behind it; (4) the irregular wave-induced seabed response is larger than that of the representative regular wave; and (5) the irregular waves with Pierson-Moscowitz $(P-M)$ spectrum introduce the most significant seabed response among various wave spectra.
\end{abstract}

Keywords: Irregular wave; pore-water pressure; wave experiments; mono-pile; seabed response 


\section{Introduction}

With the development of marine engineering and transportation, various offshore structures have been constructed in recent years, such as cross-sea bridges, offshore wind turbines and so on. Due to the complexity of the marine environment, the stability of pile foundations will also be affected not only by the direct action of wave loads, but also the response of the surrounding seabed. Waves propagation will cause periodic wave pressures on the seabed surface. Under the action of cyclic wave loading, the porewater pressures and effective stresses will change. When the pore pressure is large and the effective stress may reduce to zero, the seabed will liquefy $[1,2,3]$. The soil particles in a seabed will become loose and free after liquefaction, lose its bearing capacity, and endanger the stability of marine structures. Therefore, the study of pore-water pressure in the seabed is of great significance for the design and maintenance of marine structures.

To date, significant efforts have been devoted to the study of seabed response subject to dynamic loading $[4,5,6]$, based on Biot's poro-elastic theory [7]. Among these, Madsen [8] proposed an analytical solution for the porous seabed response under wave loads by using the expression of complex variables. The relationship between the compressibility of pore fluid and soil skeleton, soil permeability and hydraulic an-isotropy was discussed in detail. Yamamoto et al. [9] and Okusa [10] set up a analytical solution for the seabed response of infinite thickness. For the finite thickness seabed, Mei and Foda [11] also put forward a analytical solution, based on the theory of mixture.

Considering the influence of a structure, Li et al. [12] established a finite element model for the wave-induced seabed response around the pile foundation based on ABAQUS, and investigated the oscillation and accumulation of pore pressure response. The numerical simulation showed that with the decrease of the permeability coefficient, the residual pore-water pressure will increase and the amplitude of transient pore-water pressure will decrease. Furthermore, the maximum liquefaction depth occurs behind the pile foundation. However, in their study [12], the wave diffraction was not considered as only small amplitude of pile was considered. Lin et al. [13] investigated the dynamic seabed response around a pile using Finite Volume Method (FVM) model with non-linear wave loading. In their study, it was found that the pile foundation had an obvious blocking effect on the longitudinal and transverse development of pore-water pressure, thus the instantaneous liquefaction depth around the pile was reduced. However, they did not consider the self-weight of the pile. Taken the pile's self-weight into account, Sui et al. [14] developed a numerical model based on the fully 
dynamic formulations, then the seabed response around the pile was studied. Their study shows that the presence of wave diffraction and reflection has significant effects on pore-water pressure and soil displacement around the pile. Later, Asumadu et al. [15] combined Flow-3D and Comsol to investigate the wave-induced oscillatory seabed response around a mono-pile foundation.

Apart from analytical solutions and numerical simulations, experiments are also the main method to study the seabed response. Sleath [16] studied the distribution of pore-water pressure in the seabed by flume tests, then it was found that there were attenuation and phase lag of pore-water pressure along depth direction of seabed. Numerous wave experiments for transient pore pressures around marine structures have been reported in the literature $[17,18,19,20,21,22,23]$. Zen and Yamazaki [24] and Chowdhury et al. [25] carried out one-dimensional tests to investigate the transient liquefaction, and analyzed the pore-water pressure response under different wave and soil parameters. Liu et al. [26] conducted a one-dimensional cylinder test. In their study, they examined the variation of wave-induced pore-water pressure along the depth direction of sandy seabed in detail, based on which the influence of wave parameters on pore-water pressure and seabed liquefaction was analysed. In addition, Liu et al. [26] also found that with the periodical change of wave loading, there was a certain degree of settlement in sandy seabed. Because of the limitation of wave flume test equipment, the stress level may not be able to be fully simulated, so researchers began to carry out centrifuge tests. Sassa and Sekiguchi [27] investigated the wave-induced seabed liquefaction by centrifuge model tests. They found that the liquefaction did not occur when the wave loading was less than the critical stress ratio, besides, when the wave loading stopped, the density of the liquefied area increased significantly as a result of drainage consolidation. Recently, Qi and Gao [28] conducted wave flume experimental studies on pore-water pressure around a mono-pile. The relationship between the pore-water pressure and local scour was discussed. Recently, Wang et al. [29] conducted a series of wave tests for the wave-induced pore-water pressure around a mono-pile, in which the pile penetrate to half of soil layer. To authors' best knowledge, they might be the experimental data available on pore-water pressure around the pile in the literature. However, they are limited to regular wave loading,

All aforementioned studies focused on regular wave, but waves in real marine environment have a high degree of irregularity. For irregular waves, Longuet-Higgins [30] simulated the transmission process of irregular waves by superposing linear waves. Different spectra should be used to describe 
irregular waves $[31,32,33]$ for different marine environmental conditions. JONSWAP (Joint North Sea Waves Project) spectrum which is most widely used, was proposed by Hasselmann et al. [31] through a long-term observation and statistics of waves in the North Sea. It contains parameters that reflect the energy level, the frequency scale of the peak and the spectral shape. To date, there are only a few studies focused on the seabed response under irregular waves. For example, Sumer et al. [34] analysed the distribution of irregular wave-induced pore-water pressure by wave flume tests. They found that the accumulative process of pore-water pressure was similar to that in the case of regular waves. Liu and Jeng [35] established a semi-analytical solution for the response of finite thickness unsaturated seabed under irregular waves, based on which they investigated the effects of wave and soil parameters on pore-water pressure. Then the difference of seabed response between Bretschneider-Mitsuyasu (B-M) type and JONSWAP type irregular waves was compared. Recently, Xu and Dong [36] studied the liquefaction potential of sandy seabed under irregular waves by using the integrated modeling technique, and the effects of irregular waves on the accumulation of excess pore-water pressure and liquefaction process were discussed. According to Liu and Jeng [35], Xu and Dong [36], the distribution trend of irregular wave-induced pore-water pressure is alike with that of regular waves, but the amplitude of pore pressure caused by irregular wave is much larger than regular wave. Therefore, the influence of the irregular wave loading must be fully considered in the analysis of dynamic seabed response. Up to now, the experimental study on the seabed response around the mono-pile under the action of irregular waves is still blank.

In this study, a series of the irregular wave-induced pore-water pressures around a mono-pile will be conducted in a wave flume test. In the experiments, the irregular wave adopted JONSWAP spectrum first, and the pore-water pressure transducers were arranged not only along the depth direction of seabed, but also in the circumferential direction around and beneath the pile. Then, the seabed response induced by irregular waves with different spectra is also studied. In this paper, the results of a series of wave flume tests are presented, which can be used as a reference for readers to verify numerical models in the future. According to the experimental results, the distribution of pore-water pressure in the vicinity of a mono-pile under irregular waves is discussed, and the influence of wave characteristics is analyzed. 


\section{Physical modelling}

A series of experiments were carried out to study the irregular waveinduced pore-water pressure of the seabed around a mono-pile. To authors' best knowledge, only a few flume tests for a similar problem conducted by $[28,29]$ are available in the literature but they focused on regular wave loading. In the present study, the JONSWAP spectrum was used to generate the irregular waves in the first set of experiments (Tests 1-40, Table 1), and a large pile with a $30 \mathrm{~cm}$ diameter was installed at a depth of $0.6 \mathrm{~m}$ below the seabed surface. The seabed thickness is $1 \mathrm{~m}$, which allows us to measure the pore-water pressure beneath the pile. In addition, more pressure transducers were installed in the seabed, which could provide more detailed test data. In the second series of tests (Tests 41-46, Table 2), different wave spectra will be used for wave generation, from which the effects of different wave spectra on the soil response can be investigated.

\subsection{Experimental setup}

The experiments were carried out in the Wave Flume Laboratory of Southwest Jiaotong University. The dimensions of the flume are $60 \mathrm{~m}$ (length) $\times 2 \mathrm{~m}$ (width) $\times 1.8 \mathrm{~m}$ (height) as shown in Figure 1(a). The wave flume is equipped with a hydraulic piston-type wave-maker at the upstream, which can produce regular waves and irregular waves (see Figure 1(b)). The downstream of the flume is provided with a porous plastic wave absorber (see Figure 1(c)), which is used to dissipate wave energy and reduce wave reflection. Based on the technical report provided by the manufacturing company for the wave-maker and preliminary study without a structure, the efficiency of the wave absorber is at least $92 \%$. The wave-maker can generate irregular waves with a period of $0.6 \mathrm{~s}$ to $2.0 \mathrm{~s}$, and the maximum wave height can reach $0.14 \mathrm{~m}$. At the position of $21 \mathrm{~m}$ from the wave-maker is a soil tank (see Figure 1(d)), its dimensions are $7.0 \mathrm{~m}$ (length) $\times 2.0 \mathrm{~m}$ (width) $\times 1.0 \mathrm{~m}($ depth $)$. The surrounding walls and the bottom of the tank are made of rigid and impermeable concrete. In the experiment, the saturated sand bed was used to simulate the porous seabed, and the monopile model with a diameter of $30 \mathrm{~cm}$ and a height of $1.5 \mathrm{~m}$ was installed at a depth of $0.6 \mathrm{~m}$ below the seabed surface. The top and bottom ends of the pile are fixed with supports, therefore, the vibration of the pile model is not considered. The schematic figure of the test flume is given in Figure 2.

In order to measure the variation of free surface elevation and porewater pressure around the pile at the same time, wave height gauges and pore pressure transducers are installed in the wave flume. Four (4) wave 
Table 1: Wave conditions of experiments with the JONSWAP Spectrum

\begin{tabular}{|c|c|c|c|c|c|}
\hline Test No & $\begin{array}{c}\text { Wave height } \\
\left(H_{1 / 3}, \mathrm{~cm}\right)\end{array}$ & $\begin{array}{c}\text { Wave period } \\
\left(T_{1 / 3}, \mathrm{sec}\right)\end{array}$ & Test No & $\begin{array}{c}\text { Wave height } \\
\left(H_{1 / 3}, \mathrm{~cm}\right)\end{array}$ & $\begin{array}{c}\text { Wave period } \\
\left(T_{1 / 3}, \mathrm{sec}\right)\end{array}$ \\
\hline Test 1 & 4 & 0.8 & Test 22 & 10 & 0.8 \\
\hline Test 2 & 4 & 1.0 & Test 23 & 10 & 1.0 \\
\hline Test 3 & 4 & 1.2 & Test 24 & 10 & 1.2 \\
\hline Test 4 & 4 & 1.4 & Test 25 & 10 & 1.4 \\
\hline Test 5 & 4 & 1.6 & Test 26 & 10 & 1.6 \\
\hline Test 6 & 4 & 1.8 & Test 27 & 10 & 1.8 \\
\hline Test 7 & 4 & 2.0 & Test 28 & 10 & 2.0 \\
\hline Test 8 & 6 & 0.8 & & & \\
\hline Test 9 & 6 & 1.0 & Test 29 & 12 & 1.0 \\
\hline Test 10 & 6 & 1.2 & Test 30 & 12 & 1.2 \\
\hline Test 11 & 6 & 1.4 & Test 31 & 12 & 1.4 \\
\hline Test 12 & 6 & 1.6 & Test 32 & 12 & 1.6 \\
\hline Test 13 & 6 & 1.8 & Test 33 & 12 & 1.8 \\
\hline Test 14 & 6 & 2.0 & Test 34 & 12 & 2.0 \\
\hline Test 15 & 8 & 0.8 & & & \\
\hline Test 16 & 8 & 1.0 & Test 35 & 14 & 1.0 \\
\hline Test 17 & 8 & 1.2 & Test 36 & 14 & 1.2 \\
\hline Test 18 & 8 & 1.4 & Test 37 & 14 & 1.4 \\
\hline Test 19 & 8 & 1.6 & Test 38 & 14 & 1.6 \\
\hline Test 20 & 8 & 1.8 & Test 39 & 14 & 1.8 \\
\hline Test 21 & 8 & 2.0 & Test 40 & 14 & 2.0 \\
\hline
\end{tabular}

height gauges (Point 552-554 in Figure 2(b)) are designed by Yufan Co., Ltd. The measuring range of them is 0 to $0.6 \mathrm{~m}$, and the accuracy is $\pm 0.5 \%$. The arrangement of wave height gauges is shown in Figure 2(b). The porewater pressure is measured by CY306 type pore-water pressure transducers (6mm in outer diameter). The measurement range of these transducers is $30 \mathrm{kPa}$ with a accuracy of $\pm 0.1 \%$. Nineteen (19) pressure transducers (Points 1-19 in Figure 3) were set up within the seabed. Four wave pressure transducers (Points 20-23 in Figure 3) were installed along the surface of the pile model to measure the wave pressure acting on it. In this experiment, the transducers are designed and manufactured by Shengying Cekong.

\subsection{Wave conditions}

Two series of tests were carried out in this study, including (1) using JONSWAP spectrum with various wave conditions, and (2) using various 


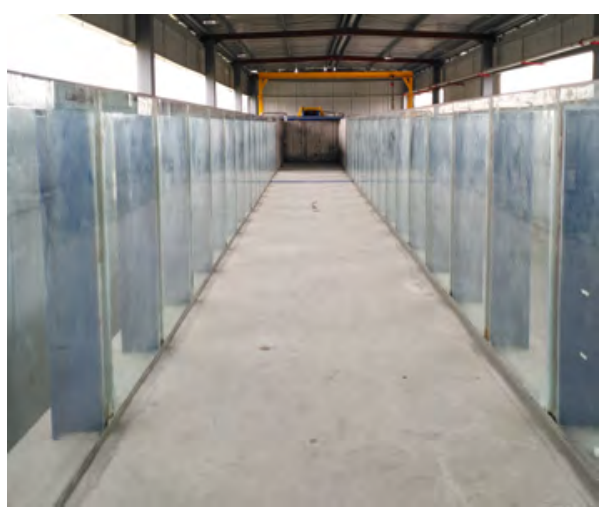

(a) wave flume

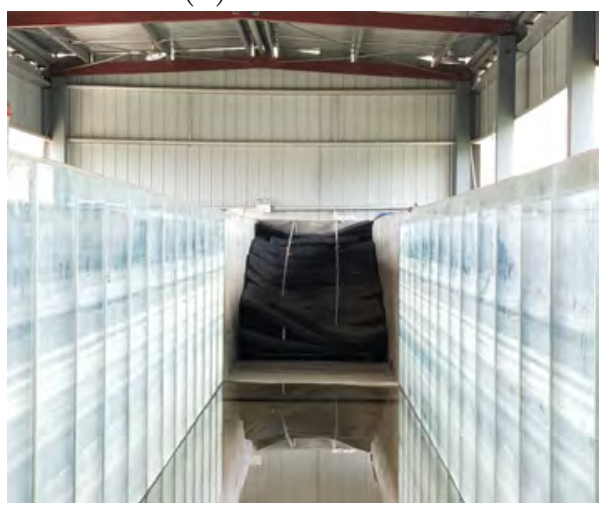

(c) wave absorber

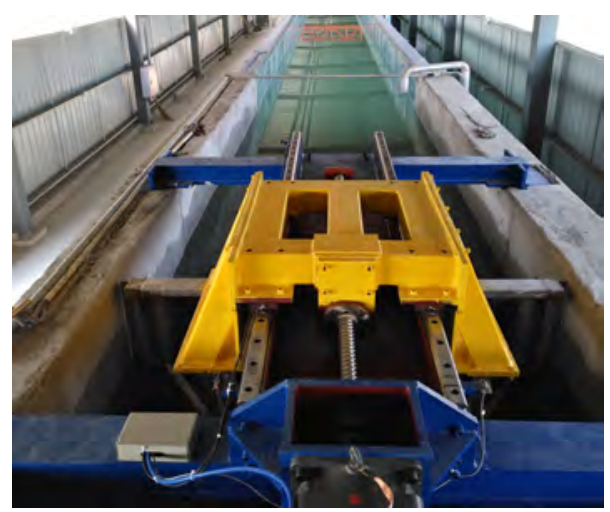

(b) wave maker

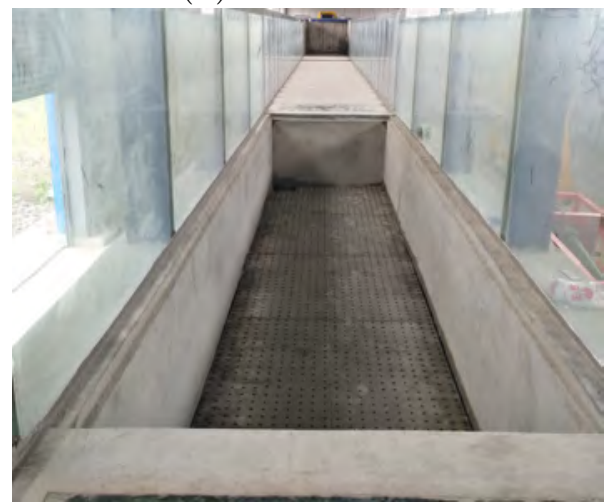

(d) soil tank

Figure 1: Photos of wave flume laboratory.

wave spectra with the same wave conditions.

In the first series of tests, according to the wave generating capacity of the test flume, forty (40) tests were conducted, and each test was repeated at least once to ensure the reliability of the measured data. The wave parameters are shown in Table 1, in which the wave height and period of irregular waves are represented by significant wave height and period. The JONSWAP spectrum $[31,37]$ was adopted in the tests. Due to the limitation of the facility, the significant wave height can only reach $10 \mathrm{~cm}$ when the significant period is $0.8 \mathrm{~s}$.

In the second series of tests, to understand the response of the seabed under irregular waves of different spectra, five (5) types of irregular waves were adopted with the significant wave height $H_{1 / 3}=10 \mathrm{~cm}$ and the period $T_{1 / 3}=1.2 \mathrm{~s}$. The wave parameters and spectra selection are shown in Table 


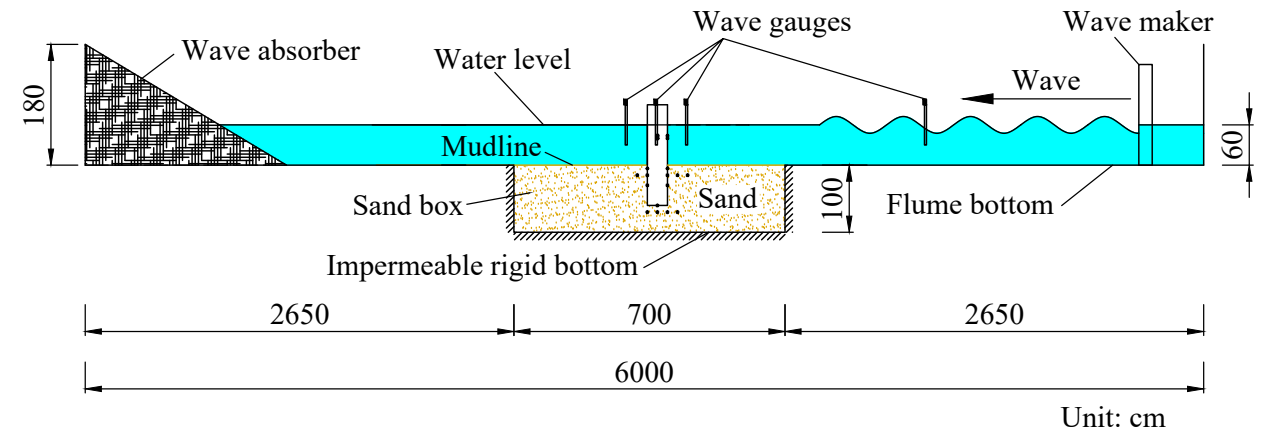

(a) Wave flume

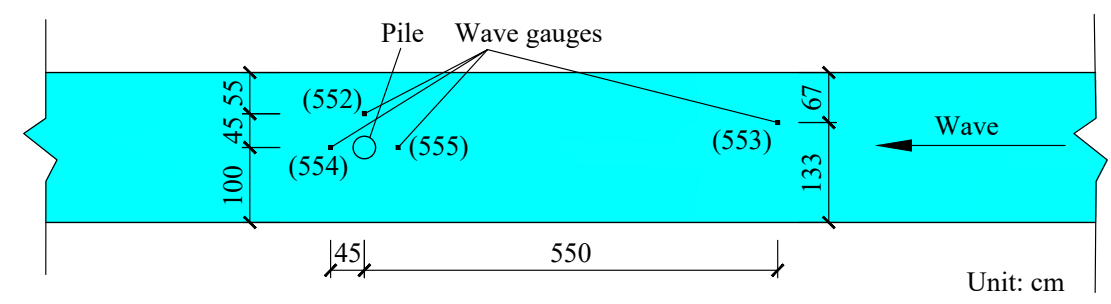

(b) Location of wave gauges

Figure 2: Experimental setup for the wave flume.

2. In all cases, the mean water depth was kept at $0.6 \mathrm{~m}$.

The frequency spectral density functions for the spectrum used in the experiments are summarised here.

\section{- JONSWAP spectrum:}

$$
\begin{gathered}
S(f)=\beta_{J} H_{1 / 3}^{2} T_{p}^{4} f^{5} \exp \left[-1.25\left(T_{p} f\right)^{-4}\right] \gamma^{\exp \left[-\left(T_{p} f-1\right)^{2} / 2 \sigma^{2}\right]} \\
\beta_{J}=\frac{0.06238}{0.23+0.033 \gamma-0.185(1.9+\gamma)^{-1}} \times[1.094-0.01915 \ln \gamma] \\
T_{p}=\frac{T_{1 / 3}}{1-0.132(\gamma+0.2)^{-0.559}} \\
\sigma= \begin{cases}0.07, & f \leq f_{p} \\
0.09, & f>f_{p}\end{cases}
\end{gathered}
$$




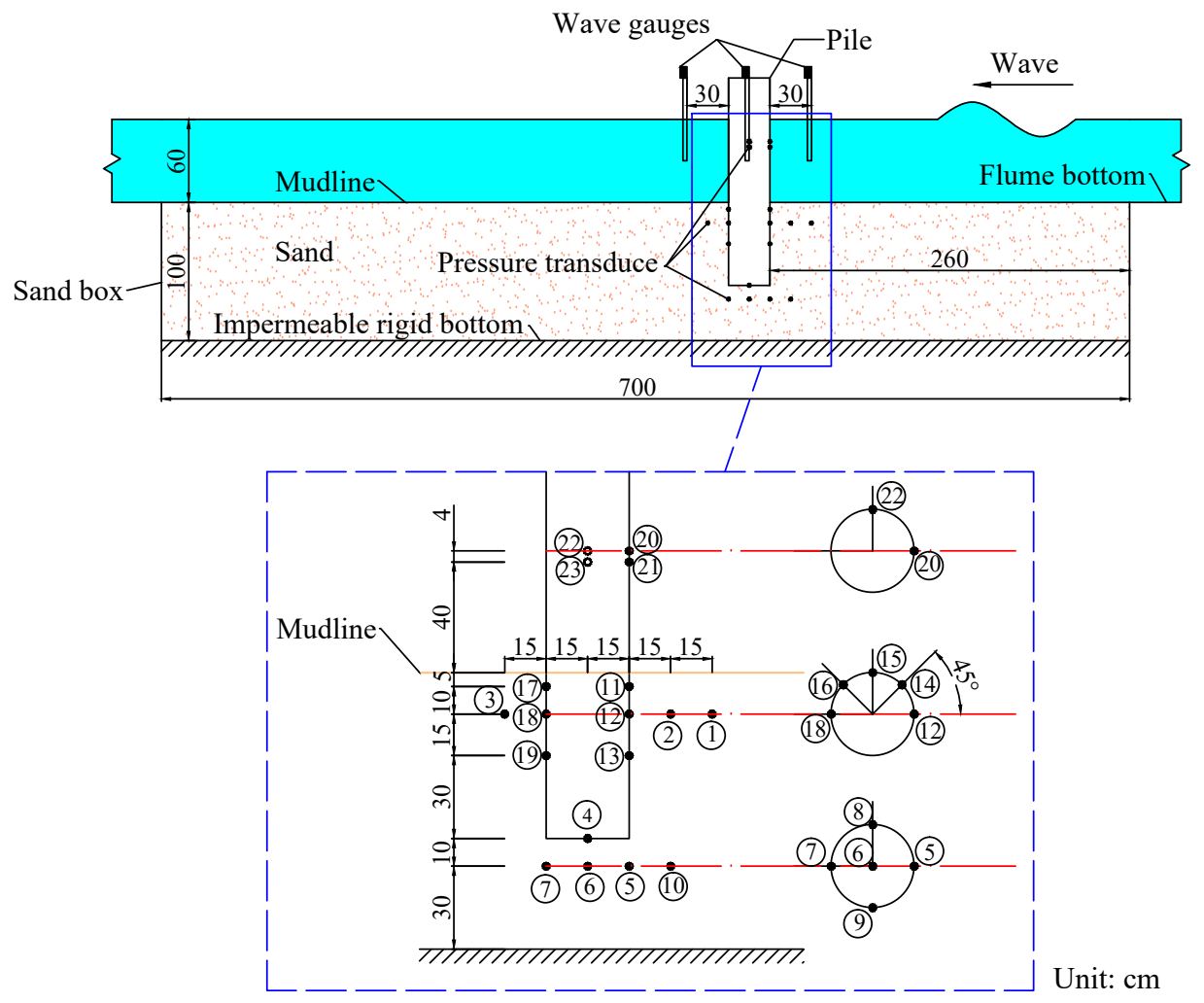

Figure 3: The arrangement of pressure transducers.

where $T_{p}$ represents the wave period corresponding to the peak point of the spectrum, and $f_{p}$ represents the wave frequency at the spectral peak, $T_{p}=1 / f_{p} . \gamma$ is the enhancement factor of spectral peak, the mean value of $\gamma=3.3$ is adopted in this study.

\section{- Bretschneider spectrum (B spectrum)}

$$
S(f)=\frac{1.25}{4} H_{1 / 3}^{2} T_{p}^{-4} f^{-5} \exp \left[-1.25\left(T_{p} f\right)^{-4}\right]
$$

where $f$ represents the wave frequency.

\section{- Pierson-Moscowitz spectrum (P-M spectrum)}


Table 2: Wave conditions and parameters used in various spectra $[31,33]$

\begin{tabular}{|c|c|c|l|}
\hline Test No & $\begin{array}{c}\text { Wave height } \\
\left(H_{1 / 3}, \mathrm{~cm}\right)\end{array}$ & $\begin{array}{c}\text { Wave period } \\
\left(T_{1 / 3}, \mathrm{sec}\right)\end{array}$ & Spectrum \\
\hline Test 41 & 10 & 1.2 & JONSWAP \\
Test 42 & 10 & 1.2 & Bretschneider \\
Test 43 & 10 & 1.2 & Pierson-Moscowitz \\
Test 44 & 10 & 1.2 & Bretchneider-Mitsuyasu \\
Test 45 & 10 & 1.2 & Wen \\
Test 46 & 10 & 1.2 & Regular wave \\
\hline
\end{tabular}

$$
S(f)=\frac{0.0005}{f^{5}} \exp \left[-\frac{0.001998}{f^{4} H_{1 / 3}^{2}}\right],
$$

\section{- Bretchneider-Mitsuyasu spectrum (B-M spectrum)}

$$
S(f)=0.257 H_{1 / 3}^{2} T_{1 / 3}^{-4} f^{-5} \exp \left[-1.03\left(T_{1 / 3} f\right)^{-4}\right]
$$

193

- Wen's spectrum

$$
\begin{aligned}
0 \leq f \leq & 1.05 / T_{1 / 3}, \\
S(f)= & 0.0687 H_{1 / 3}^{2} T_{1 / 3} P \exp \left\{-95 \times\left(1.1 T_{1 / 3} f-1\right)^{12 / 5}\right. \\
\times & {\left.\left[\ln \frac{P\left(5.813-5.137 H^{*}\right)}{\left(6.77-1.088 P+0.13 P^{2}\right)\left(1.307-1.426 H^{*}\right)}\right]\right\} } \\
f> & 1.05 / T_{1 / 3}, \\
S(f)= & 0.0687 H_{1 / 3}^{2} T_{1 / 3}\left(\frac{1.05}{T_{1 / 3} f}\right)^{4-2 H^{*}} \\
& \times \frac{\left(6.77-1.088 P+0.13 P^{2}\right)\left(1.307-1.426 H^{*}\right)}{5.813-5.137 H^{*}} \\
P= & 95.3 \frac{H_{1 / 3}^{1.35}}{T_{1 / 3}^{2.7}}, \quad H^{*}=0.626 \frac{H_{1 / 3}}{h}
\end{aligned}
$$

where $h$ is the mean water depth. $P$ represents the sharpness factor, a measure of spectral width; $H^{*}$ is the influence factor of water depth. 


\subsection{Properties of seabed sediments}

This study mainly focuses on the transient seabed response, therefore, the sandy sediment (quartz sand) with the average particle size $d_{50}=0.215$ $\mathrm{mm}$ was utilized as the seabed material. The soil properties were measured by a series of standard laboratory experiments. The particle size distribution of soil sample (as shown in Figure 4) was measured by sieving analysis. The grain density of the soil $\left(\rho_{s}=m_{s} / V_{s}\right)$ was obtained by the flask method, i.e., measured the volume of water drained by soil particles, which denoted the volume of sand particles $\left(V_{s}\right)$, and $m_{s}$ represented the dry mass of the soil. Permeability $\left(k_{s}\right)$ was determined by using a constant head permeability measuring instrument. The elastic modulus $(E)$ was measured by the triaxial apparatus, the Poisson's ratio of soil $\left(\mu_{s}\right)$ used empirical value 0.3 , then the shear modulus $(G)$ was calculated by elastic modulus and Poisson's ratio. By measuring the loose density and compaction density of soil, the maximum void ratio $\left(e_{\max }\right)$ and minimum void ratio $\left(e_{\min }\right)$ were calculated. The main soil properties are listed in Table 3.

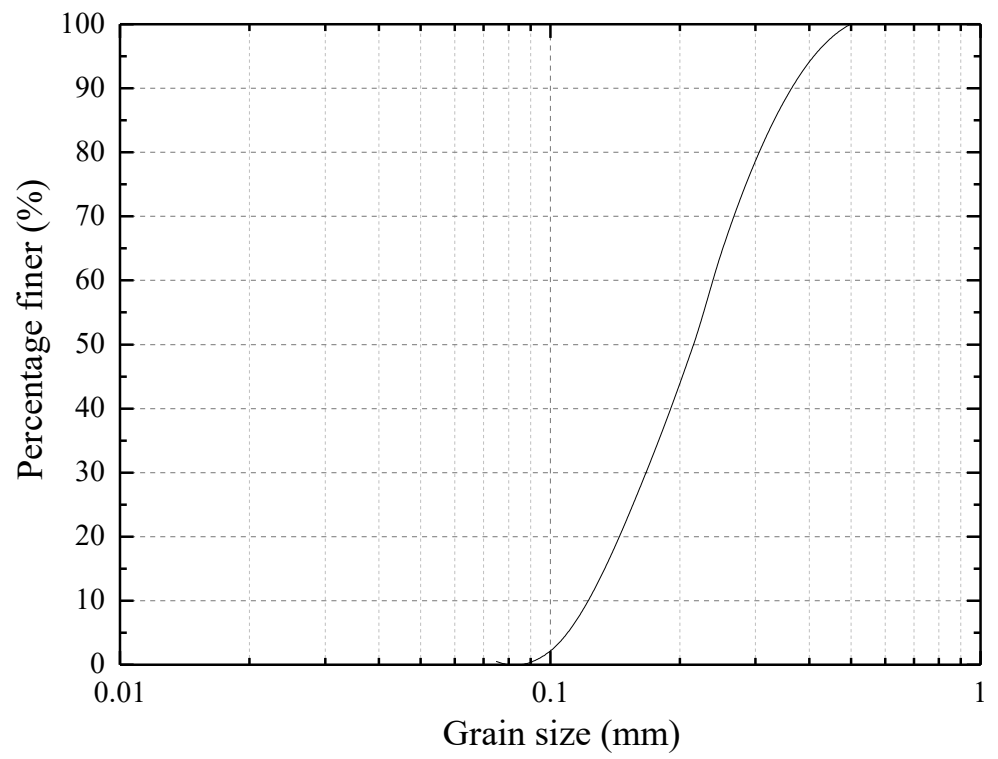

Figure 4: Grain size distribution of soil sample.

\subsection{Testing procedure}

The testing procedure is outlined as follows: 
Table 3: Properties of soil used in the experiments.

\begin{tabular}{|c|c|c|}
\hline Soil properties & Value & unit \\
\hline Grain density $\left(\rho_{s}\right)$ & 2679 & $\mathrm{~kg} / \mathrm{m}^{3}$ \\
Permeability $\left(k_{s}\right)$ & 0.002382 & $\mathrm{~m} / \mathrm{s}$ \\
Poisson ratio $\left(\mu_{s}\right)$ & 0.3 & - \\
Shear modulus $(G)$ & $8.58 \times 10^{6}$ & $\mathrm{~N} / \mathrm{m}^{2}$ \\
Soil porosity $(n)$ & 0.448 & - \\
Void ratio $(e)$ & 0.812 & - \\
Maximum void ratio $\left(e_{\max }\right)$ & 0.892 & - \\
Minimum void ratio $\left(e_{\min }\right)$ & 0.643 & - \\
Relative density $\left(D_{r}\right)$ & 0.321 & - \\
Mean size of grain $\left(d_{50}\right)$ & 0.215 & $\mathrm{~mm}$ \\
\hline
\end{tabular}

1. Installation of the mono-pile and measuring instruments: After cleaning the flume and soil tank, 4 wave height gauges and 23 pressure transducers were set up in the locations shown in Figure 2 and Figure 3 . Since the pressure transducers are equipped with sand filters, they should be submerged in water for 24 hours in advance to ensure that the air is completely exhausted. The model was installed in the middle of the soil tank with a fixed frame, at the location of $0.6 \mathrm{~m}$ below the seabed surface.

2. Preparation of the experimental seabed: Prior to the test, a large amount of sand was slowly poured into the sand tank, and water was gradually added with continuous stirring. Placing the mixture in the test section to consolidate for at least 3 days and then a soil layer with a thickness of about $1.0 \mathrm{~m}$ was produced. Finally, the seabed surface was leveled with a scraper.

3. Filling the water tank: Opened the intake valve and slowly poured water until the water depth reached $0.6 \mathrm{~m}$.

4. Turning on the wave-maker and generating irregular waves.

5. Acquisition of test data: After the irregular wave produced in the flume was stable, sampling the statistics of pore-water pressure and wave height at the same time, and the data acquisition duration is at least $240 \mathrm{~s}$.

6. Turning off the wave-maker.

7. Repeating the test.

8. Steps 4 to 7 were repeated for the next case. 


\section{Wave profiles near the mono-pile}

In this study, four wave height gauges were installed in the experimental section. As shown in Figure 2. The far-field gauge (gauge 553 in Figure 2(b)) was installed at $5.5 \mathrm{~m}$ from the center of the pile, which was used for the measurement of incident wave height. The remaining three gauges (gauges $552,554,555$ in Figure 2(b)) were located $30 \mathrm{~cm}$ from the pile center, which were used to measure the wave height around the pile. In this section, the significant wave height is $10 \mathrm{~cm}$, and the significant period is $1.2 \mathrm{~s}$, the mean water depth is $0.6 \mathrm{~m}$.

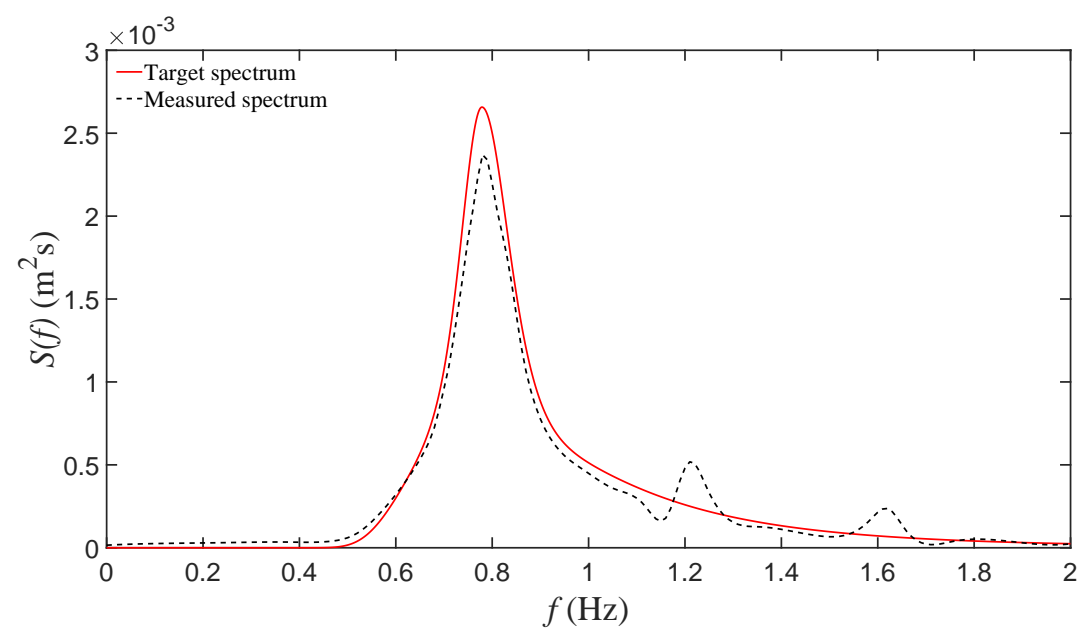

Figure 5: Comparison of measured spectrum and target spectrum for Test $24\left(H_{1 / 3}=10\right.$ $\left.\mathrm{cm}, T_{1 / 3}=1.2 \mathrm{~s}\right)$.

To ensure the accuracy of wave generation, it is necessary to analyze the frequency spectrum of the measured wave profile (measured by gauge 553) and compare it with the target spectrum. Herein, the Fourier transform was used to analyze the spectrum of experimental data. Figure 5 shows the comparison between the smoothed measured spectrum and the target spectrum (JONSWAP spectrum). It can be seen from the figure that except for small deviations at some frequencies, the measured spectrum is basically consistent with the target spectrum. This indicates that the wave-making function of the test flume is reliable. Note that the wave measured by gauge 553 can be approximately considered as the incident wave. However, another point of view would be the physics of the process under observation itself, namely the pore-water pressures. That process can be studied, at least from 
the scope of impulse-response, regardless the nature of the waves (incident or total). A different question would be that if we would be looking for an accurate energy budget, because in that case it would be necessary to separate incident from reflected. This requires a further detailed investigation in the furtume rrhish is nut of annnn of thic otuder
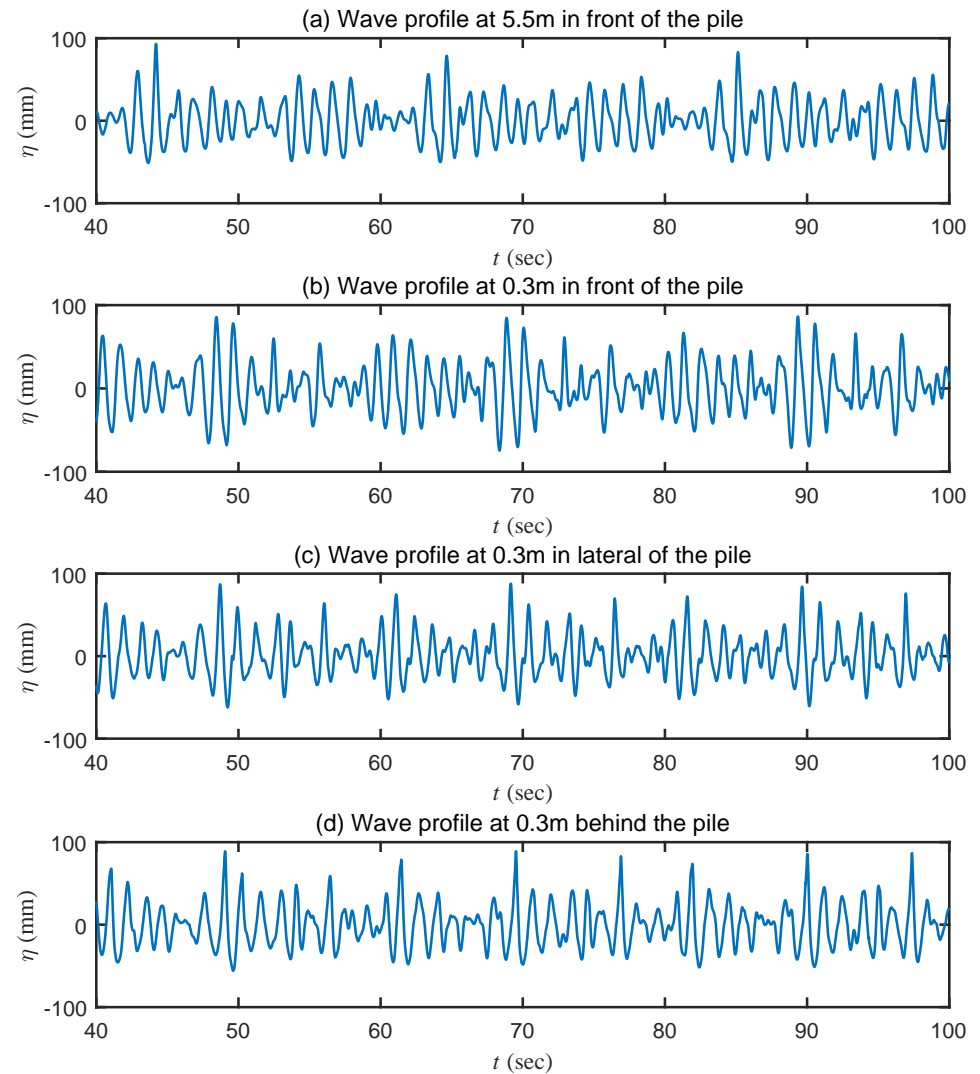

Figure 6: Distribution of wave profiles vs time for Test $24\left(H_{1 / 3}=10 \mathrm{~cm}, T_{1 / 3}=1.2 \mathrm{~s}\right)$.

Figure 6(a) plots the wave profile measured by the far-field wave height gauge (gauge 553 in Figure 2(b)). Figure 6(b)-(d) shows the wave profiles around the mono-pile (gauges 552, 554 and 555 in Figure 2(b)). Since it takes some time for the wave to stabilize, only the measured results after $40 \mathrm{~s}$ are presented in the figure. Compared with the incident wave, when the wave propagates to the front of the pile, the wave crest will rise. This is because the interactions between the incident and reflected waves, and part of the kinetic energy is converted into the potential energy. In addition, the 
wave surface around the mono-pile are slightly deformed, which is caused by wave diffraction.

\section{Pore-water pressures in a seabed}

In this section, the results of irregular wave-induced pore-water pressure in seabed around a mono-pile are presented. Based on the measured data, the distribution of pore-water pressure around the pile is discussed, and the influence of wave parameters on seabed response is analyzed. Note that $h$ represents the thickness of the seabed, $p_{0}=\gamma_{w} d$ is the static water pressure acting on the seabed surface, where $\gamma_{w}$ is the unit weight of water and $d$ is the depth of water. The center of the pile on the seabed surface is taken as the coordinate point, the $x$-axis direction points to upstream, and the $z$-axis is positive upward from the seabed surface. The pore-water pressures presented in this paper are those cause by dynamic wave pressures, in which the hydrostatic pressures were deducted.

\subsection{Along the depth of a seabed}

In this section, we investigate soil response versus soil depth with the cases of (1) in front of the mono-pile and (2) behind the mono-pile.

Figure 7 shows the time-varying pore-water pressure at the front side of the pile $(x=0.15 \mathrm{~m})$ under irregular wave action. The pressure transducers 11, 12, 13 and 5 were fixed on the pile wall as shown in Figure 3. It can be seen from the figure that there is an obvious attenuation phenomenon as the depth increases. The maximum pore-water pressure at Point 11 ( $z=-$ $0.05 \mathrm{~m})$ is about three times that at Point $12(z=-0.15 \mathrm{~m})$. Comparing the results, a phase lag between different measuring points is observed. The main reason for the phase lag is that the seabed is a two-phase medium consisting of fluid and solid. The attenuation and phase lag of pore-water pressure are similar to regular wave-induced seabed response $[10,16]$. For an irregular wave, this phenomenon was previously reported by Liu and Jeng [35] with their semi-analytical solutions, and it had also been observed in the present experiment.

To obtain the distribution of the pore-water pressures caused by irregular waves more intuitively, and examine the influence of wave parameters on seabed response, Figure 8 plots the distribution of the maximum porewater pressure $\left(p_{m} / p_{0}\right)$ versus seabed depth $(z / h)$ in various significant wave heights for a period $T_{1 / 3}=2.0 \mathrm{~s}$. The experimental results for $H_{1 / 3}=6 \mathrm{~cm}, 8$ $\mathrm{cm}, 10 \mathrm{~cm}$ and $12 \mathrm{~cm}$ are presented in the figure. The irregular wave-induced maximum pore-water pressure decreases with the increase of seabed depth 


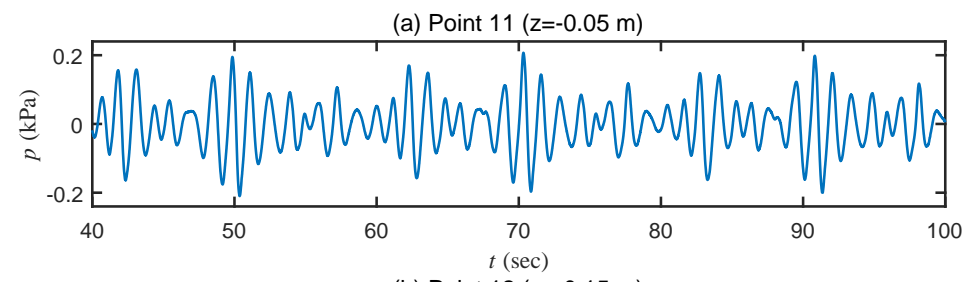

(b) Point $12(\mathrm{z}=-0.15 \mathrm{~m})$
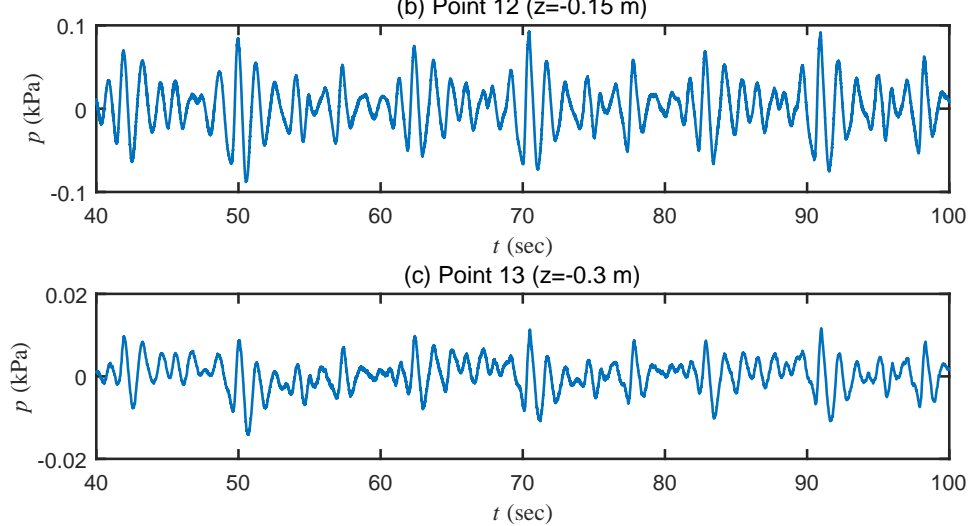

(d) Point $5(\mathrm{z}=-0.7 \mathrm{~m})$

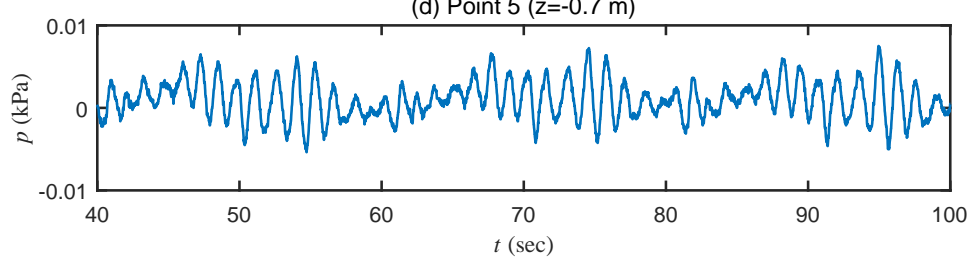

Figure 7: Distribution of pore-water pressures vs time along the front side of pile for Test $24\left(x=0.15 \mathrm{~m}, H_{1 / 3}=10 \mathrm{~cm}, T_{1 / 3}=1.2 \mathrm{~s}\right.$, Point $\left.11,12,13 \& 5\right)$.

as shown in Figure 8, which may be caused by the gradual dissipation of the pore-water pressure. And the attenuation rate decreases with the soil depth increasing. In addition, as the increase of effective wave height, the maximum pore-water pressure increases, which is because the wave energy acting on the seabed surface become larger and larger $\left(E \approx H^{2} L, L\right.$ stands for the wave length), thus enhancing the seabed response around the pile. Especially when the depth is less than $0.3 \mathrm{~m}$, this effect is more significant. For the region below $0.3 \mathrm{~m}$, the influence becomes insignificant.

Figure 9 illustrates the effect of significant period on the maximum porewater pressure for $H_{1 / 3}=14 \mathrm{~cm}$. Since the irregular wave of $H_{1 / 3}=14 \mathrm{~cm}$ can not be generated when $T_{1 / 3}=0.8 \mathrm{~s}$, only the results for $T_{1 / 3}=1.0 \mathrm{~s}, 1.2$ $\mathrm{s}, 1.6 \mathrm{~s}$ and $2.0 \mathrm{~s}$ are presented. As shown in Figure 9, the maximum 


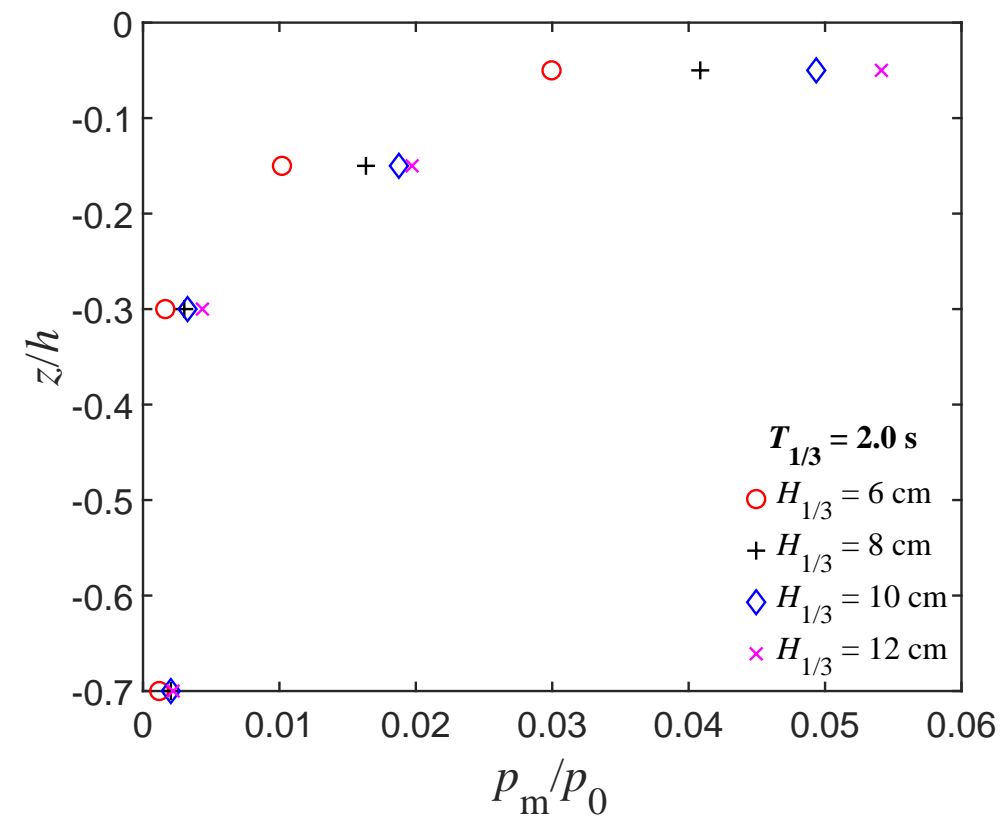

Figure 8: Distribution of the maximum pore-water pressure vs seabed depth ( $\mathrm{z})$ along the front side of pile for various wave heights $\left(x=0.15 \mathrm{~m}, T_{1 / 3}=2.0 \mathrm{~s}\right.$, Point $\left.11,12,13 \& 5\right)$

pore pressure also decreases with the increase of seabed depth, and the attenuation rate becomes smaller and smaller. With the significant period increasing, the maximum pore-water pressure increases. This is because the period increasing will change the wave length and wave number, resulting in the enlargement of wave pressure which can aggravate the seabed response. This effect becomes more obvious when the depth is less than $0.3 \mathrm{~m}$.

In order to investigate the seabed response behind the pile, the time series of pore-water pressure at the cross-section behind the pile $(x=-0.15$ $\mathrm{m}$ ) is presented in Figure 10. The pressure transducers 17, 18, 19 and 7 were fixed on the pile wall as shown in Figure 3. Comparing Figure 7 and Figure 10, the time-varying curve of pore-water pressure is similar to that in front of the pile, but the pore pressure is smaller than it.

Figure 11 and Figure 12 illustrate the vertical distribution of the maximum pore-water pressure $\left(p_{m} / p_{0}\right)$ versus seabed depth $(z / h)$ for various significant wave heights and periods. Compared with Figure 8 and Figure 9 , the variation trend of pore-water pressure behind the pile is similar to that in front of the pile. Furthermore, the influence of wave parameters on 


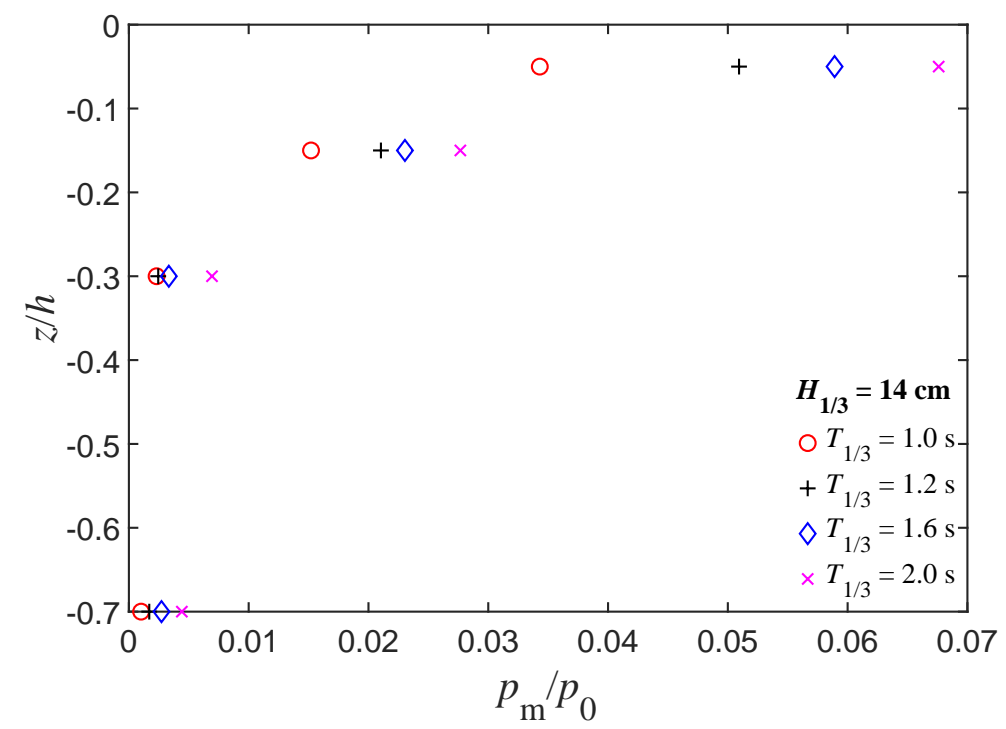

Figure 9: Distribution of the maximum pore-water pressure vs seabed depth ( $\mathrm{z}$ ) along the front side of pile for various wave heights $\left(x=0.15 \mathrm{~m}, H_{1 / 3}=14 \mathrm{~cm}\right.$, Point $\left.11,12,13 \& 5\right)$

pore pressure is the same. The maximum pore-water pressure increases with the increase of significant wave height and period. However, the pore-water pressure behind the pile is much smaller than that in front of the pile. This phenomenon is consistent with the experimental results of Qi and Gao [28], which is measured under the action of regular waves. The reason may be that due to the interactions between the incident wave and the reflected wave, the wave crest and the wave pressure in front of the pile will increase, resulting in a larger pore-water pressure in the seabed. Besides, on the back side of the pile, the pore-water pressure decreases attributed to the influence of the large-scale wake vortices.

\subsection{Around the mono-pile}

In the present study, we installed five pressure transducers around the mono-pile at the depth of $0.15 \mathrm{~m}$. The pressure transducers $12,14,15,16$ and 18 were fixed on the pile wall as shown in Figure 3. Figure 13 plots the distribution of the maximum pore-water pressure around the pile for various significant wave heights for $T_{1 / 3}=2.0 \mathrm{~s}$ at the seabed depth $z=-$ $0.15 \mathrm{~m}$. In the figure, $0^{\circ}$ represents the front side of the pile, and $180^{\circ}$ represents the back side of the pile. As shown in the figure, the largest pore pressure occurs in front of the pile, while the smallest occurs behind the pile. 
(a) Point $17(z=-0.05 \mathrm{~m})$

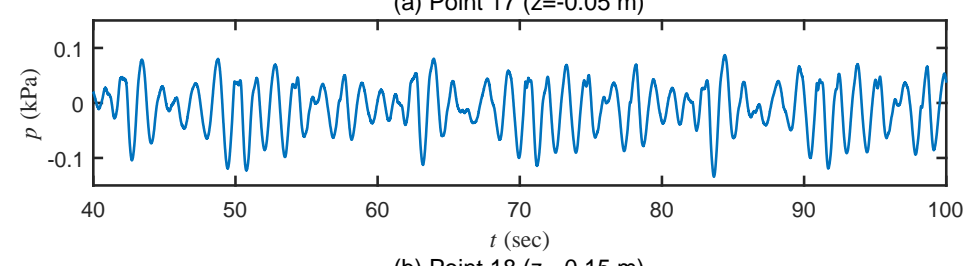

(b) Point $18(z=-0.15 \mathrm{~m})$



(c) Point $19(\mathrm{z}=-0.3 \mathrm{~m})$

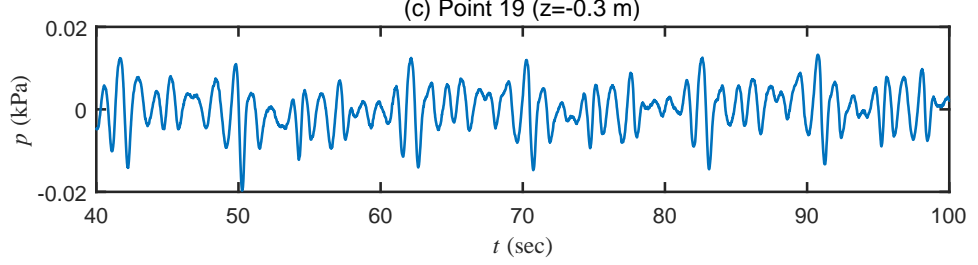

(d) Point 7 ( $z=-0.7 \mathrm{~m})$

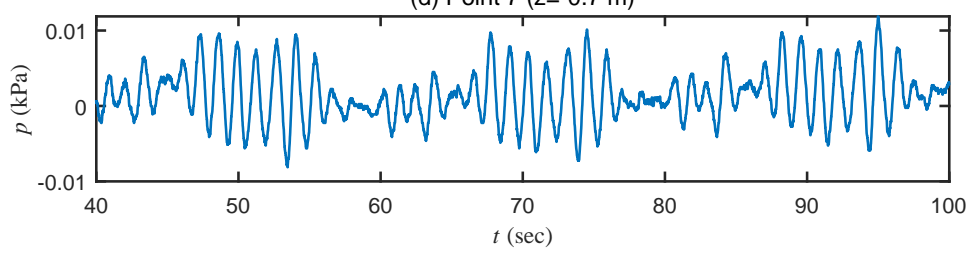

Figure 10: Distribution of pore-water pressures vs time along the back side of pile for Test $24\left(x=-0.15 \mathrm{~m}, H_{1 / 3}=10 \mathrm{~cm}, T_{1 / 3}=1.2 \mathrm{~s}\right.$, Points $\left.17,18,19 \& 7\right)$.

Besides, the maximum pore-water pressure decreases continuously from $0^{\circ}$ to $180^{\circ}$ along the circumferential direction of the pile. This may be caused by wave reflection and diffraction. The interaction between incident wave and reflected wave in front of the pile leads to the rise of wave crest, which in turn increases the pore-water pressure. While in the process of wave propagating through the pile, the wave energy gradually dissipates due to wave diffraction, resulting in the decrease of pore pressure on the lateral side of pile.

Figure 14 illustrates the effect of significant period on the maximum porewater pressure around the pile when the significant wave height $H_{1 / 3}=14 \mathrm{~cm}$ and the seabed depth $z=-0.15 \mathrm{~m}$. As shown in the figure, the pore-water pressure increases with the increase of the period, and decreases with the 


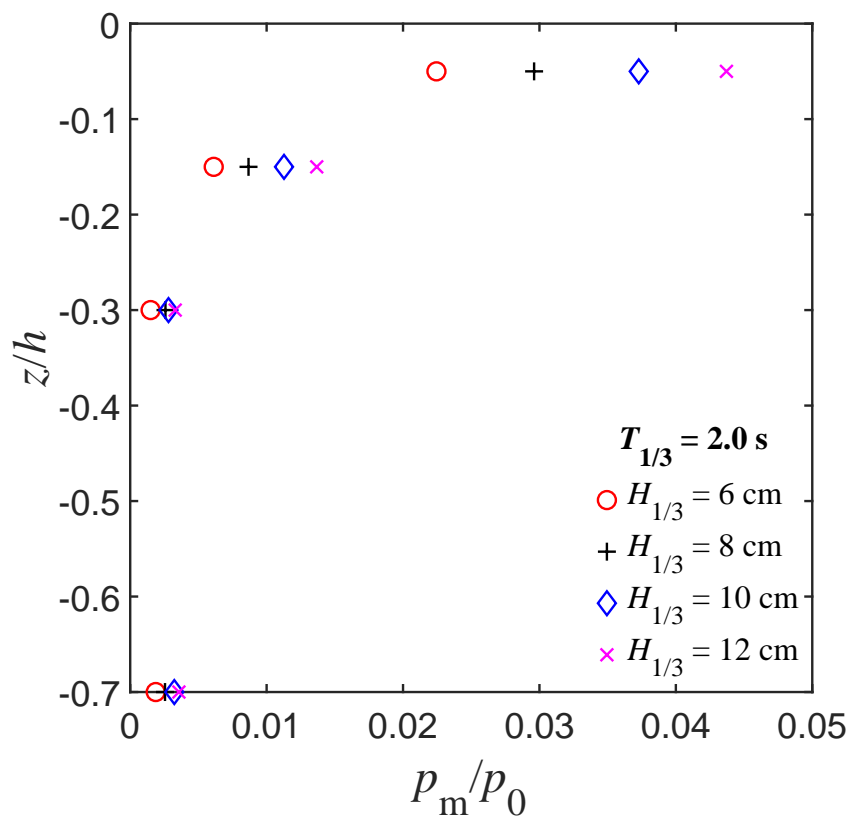

Figure 11: Distribution of the maximum pore-water pressure vs seabed depth $(z)$ behind the pile for various wave heights $\left(x=-0.15 \mathrm{~m}, T_{1 / 3}=2.0 \mathrm{~s}\right.$, Points $\left.17,18,19 \& 7\right)$.

increase of the angle. On the lateral and back sides of the pile, the larger the period is, the faster the pore-water pressure increases. However, it is found that with the increase of significant wave height and period, the influence of them on pore-water pressure in front of the pile becomes smaller and smaller. This may be attributed to the wave reflection occurred there.

\subsection{Beneath the center of the mono-pile}

As mentioned previously, in this study, the mono-pile is placed at a depth of $0.6 \mathrm{~m}$ below the seabed surface, so that the pore-water pressure beneath the pile can be examined. The researches in this field are still blank. In our experiments, five pressure transducers were installed at $z=-0.7 \mathrm{~m}$, which is $0.1 \mathrm{~m}$ below the bottom of the pile, for five points: Points 5, 6, 7, 8 and 9 in Figure 3. In the process of experiment, there were some problems to the No.6 and No.9 pressure transducers, so these two transducers were not considered. Figure 15 presents the distribution of maximum pore-water pressure for various significant wave heights for $T_{1 / 3}=2.0 \mathrm{~s}$ at $z=-0.7 \mathrm{~m}$. The figure shows that the pore-water pressure beneath the pile increases 


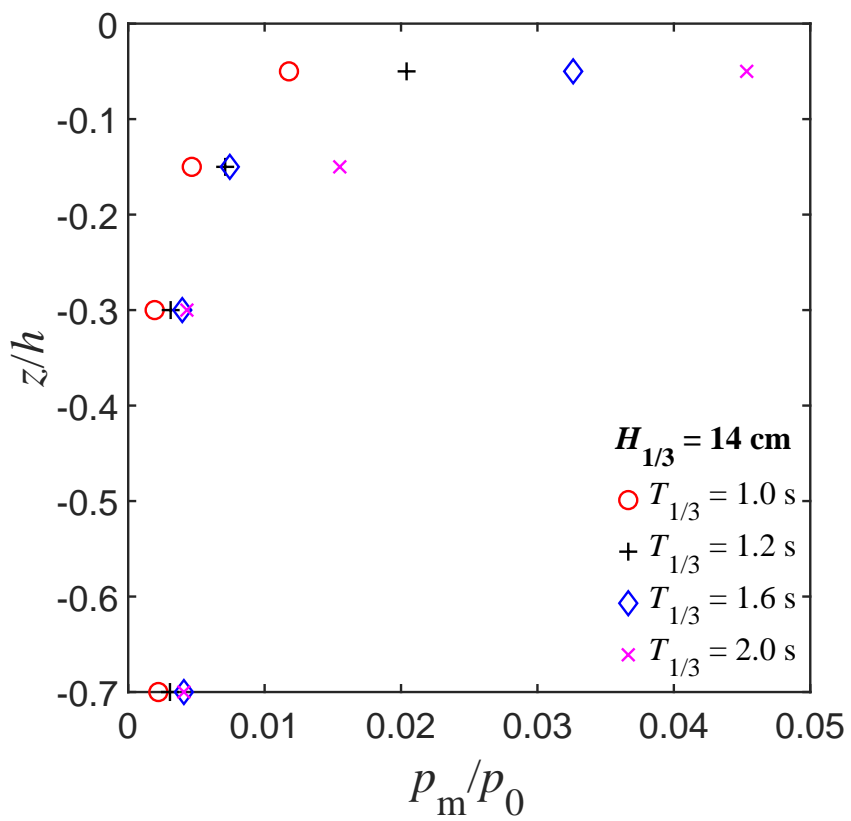

Figure 12: Distribution of the maximum pore-water pressure vs seabed depth $(z)$ behind the pile for various wave periods $\left(x=-0.15 \mathrm{~m}, H_{1 / 3}=14 \mathrm{~cm}, T_{1 / 3}=1.2 \mathrm{~s}\right.$, Points 17,18 ,

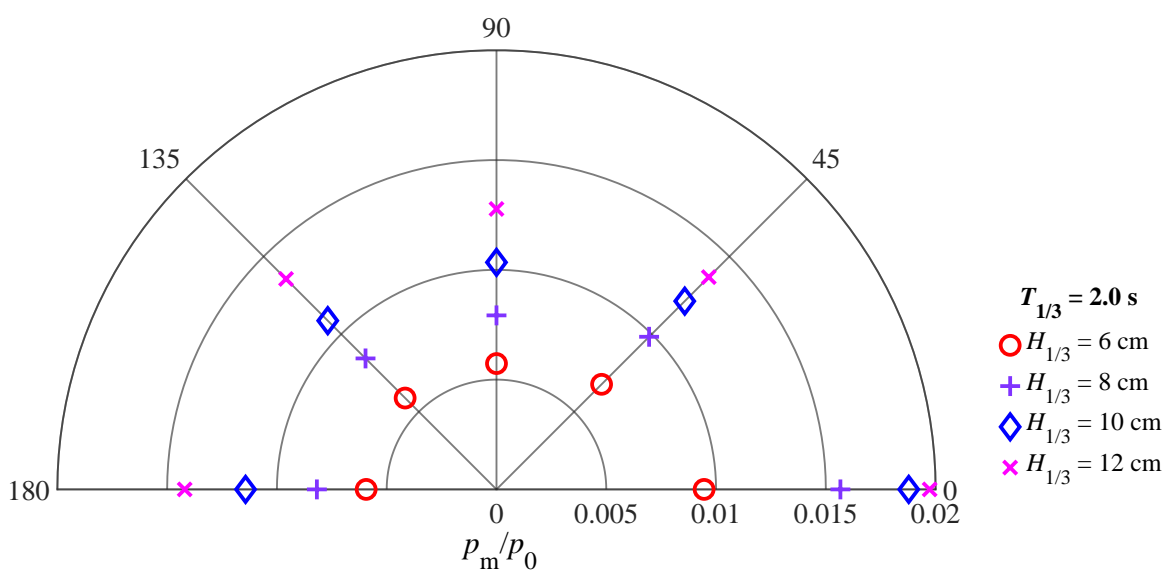

Figure 13: Distribution of the maximum pore-water pressures around the pile for various wave heights at $z=-0.15 \mathrm{~m}\left(T_{1 / 3}=2.0 \mathrm{~s}\right.$, Point $\left.12,14,15,16 \& 18\right)$.

with the increase of effective wave height. However, the maximum pore- 


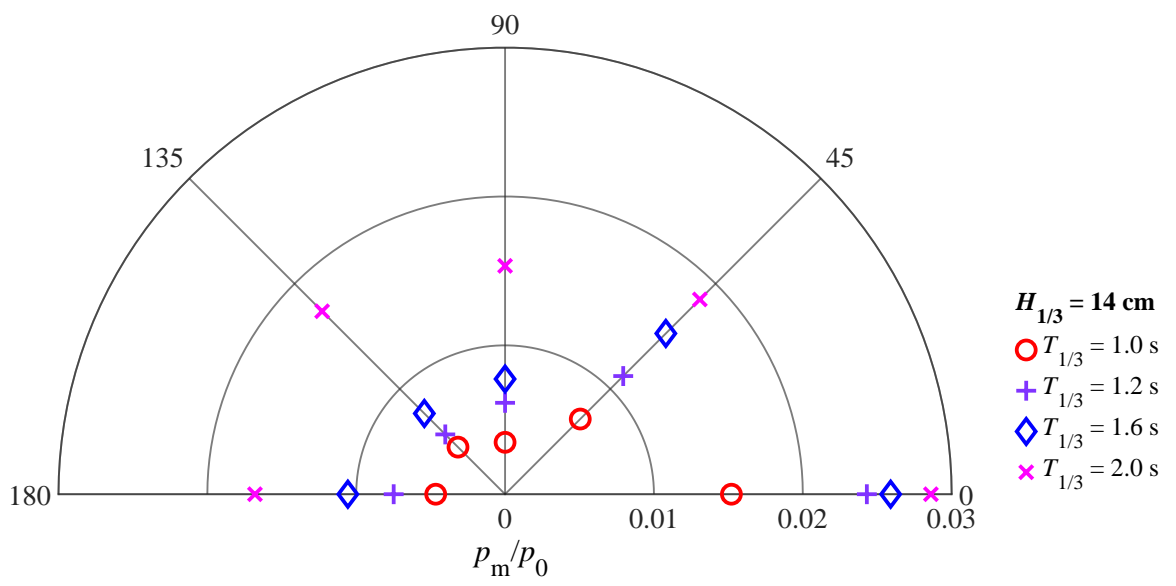

Figure 14: Distribution of the maximum pore-water pressures around the pile for various wave heights at $z=-0.15 \mathrm{~m}\left(H_{1 / 3}=14 \mathrm{~cm}\right.$, Points $\left.12,14,15,16 \& 18\right)$.

water pressure behind the pile is the largest, while that in front of the pile is the smallest. The maximum pore-water pressure increases from $0^{\circ}$ to $180^{\circ}$ around the pile. Note that the distribution of pore-water pressure is opposite to that at $z=-0.15 \mathrm{~m}$, and the magnitude of pore-water pressure

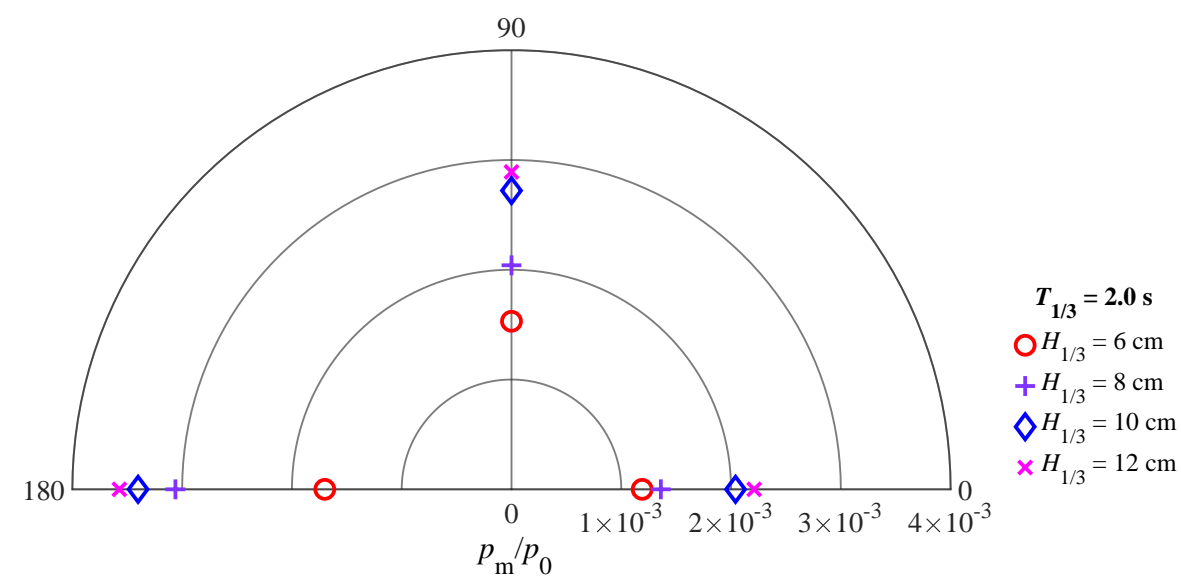

Figure 15: Distribution of the maximum pore-water pressures around the pile for various wave heights at $z=-0.70 \mathrm{~m}\left(T_{1 / 3}=2.0 \mathrm{~s}\right.$, Point $\left.5,8 \& 7\right)$.

Figure 16 illustrates the effect of significant period on maximum porewater pressure beneath the pile for $H_{1 / 3}=14 \mathrm{~cm}$ at $z=-0.7 \mathrm{~m}$. It can be 


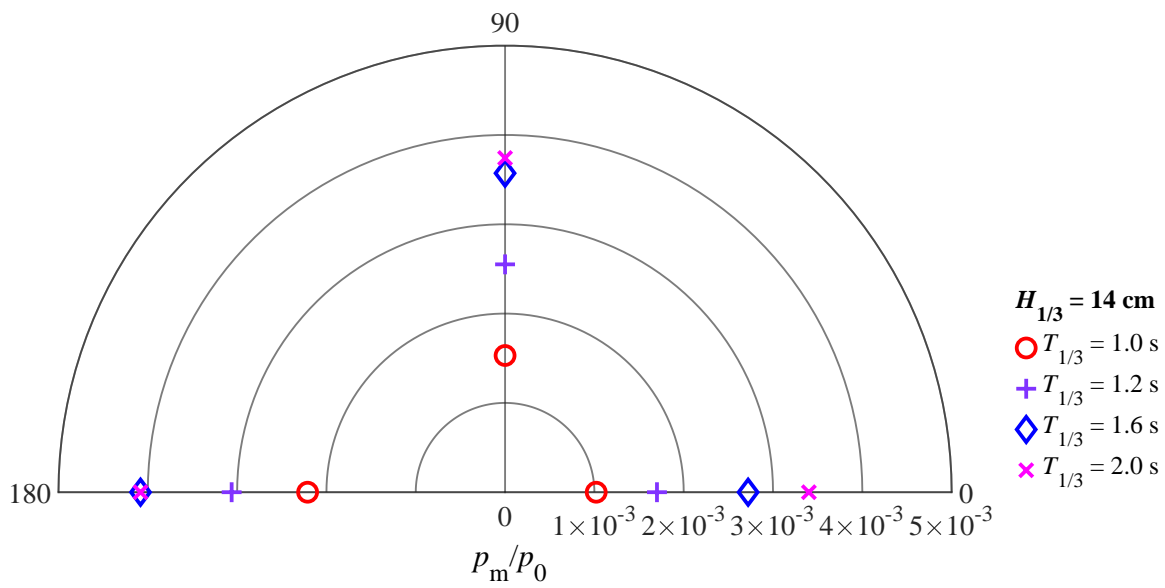

Figure 16: Distribution of the maximum pore-water pressures around the pile for various wave heights at $z=-0.70 \mathrm{~m}\left(H_{1 / 3}=14 \mathrm{~cm}\right.$, Point $\left.5,8 \& 7\right)$.

seen from the figure that with the increase of significant period, the porewater pressure beneath the pile increases. However, with the increase of the wave period, the pore-water pressure increases more and more slowly, which shows that the influence of significant period is non-linear. As shown in Figure 15 and Figure 16, significant wave height and wave period have a noticeable impact on pore-water pressure beneath the bottom of the pile.

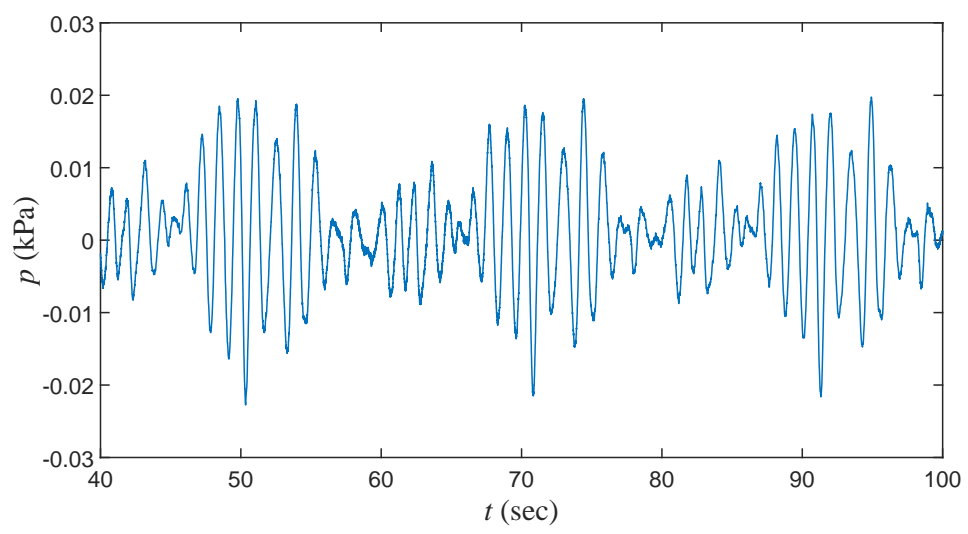

Figure 17: Distribution of pore-water pressures vs time beneath the center of the pile's bottom for Test $24\left(x=40 \mathrm{~cm}, z=-0.6 \mathrm{~m}, H_{1 / 3}=10 \mathrm{~cm}, T_{1 / 3}=1.2 \mathrm{~s}\right.$, Point 4$)$.

Another interesting result is from the measurement point 4 (see Figure

3 ) at the center of the pile's bottom. It is noted that the measurement at the 
point beneath a mono-pile has not been reported in the previous research available in the literature. Figure 17 shows the time series of pore-water pressure at Point 4 under irregular wave action. As shown in the figure, although there is no direct wave pressure acting on the seabed surface above Point 4, the distribution of pore pressure is still oscillatory, indicating that pore-water pressures are transferred from the nearby soil to this point.

To intuitively understand the nature of pore water pressure at the bottom of the pile (Point 4), Figure 18(a) presents the influence of significant wave height and wave number on pore-water pressures at Point 4 . As a reference, the variations of pore-water pressure near the seabed surface at Point 11 and Point 17 are also presented in Figure 18(b)-(c). The wave number was calculated according to the linear wave dispersion relation. Comparing these figures, the pore-water pressure near the seabed surface (Point 11 and Point 17) is much larger than that at the bottom of the pile, which is because the pore pressure decreases with the increase of the seabed depth. Furthermore, it can also be found that wave parameters have a significant effect on irregular wave-induced pore pressures. The larger the significant wave height is, the larger the pore-water pressure is, and the pore pressure decreases with the increase of the wave number. Furthermore, the wave number and pore-water pressure near the seabed surface are approximately linearly related within a certain range $\left(1.51 \mathrm{~m}^{-1} \leq k \leq 2.11 \mathrm{~m}^{-1}\right)$. However, there are some unusual pressures at the bottom of the pile for $k=2.11 \mathrm{~m}^{-1}$ when significant wave height is small, the same phenomenon is also found in repeated tests. This requires further investigations in the future.

\section{Seabed response with various wave spectra}

In different ocean environments, different spectra should be utilized to describe irregular waves. To investigate the seabed response under the action of different spectral irregular waves, six tests (including one test for regular wave) were carried out, as listed in Table 2. The pore-water pressures around the mono-pile under the action of regular wave and various spectral irregular waves were measured. To make comparison between regular wave and irregular wave, it is necessary to consider how to define the appropriate regular wave parameters to represent the corresponding irregular wave. Based on the Liu and Jeng [35], the significant wave height and period were taken as the representative parameters for regular waves. The irregular wave spectra and wave parameters adopted are listed in Table 2.

Figure 19 plots the time series of pore-water pressure measured by No.11 pressure transducer under various waves. The dashed lines represent the up- 
(a) At the bottom of the pile (Point 4)
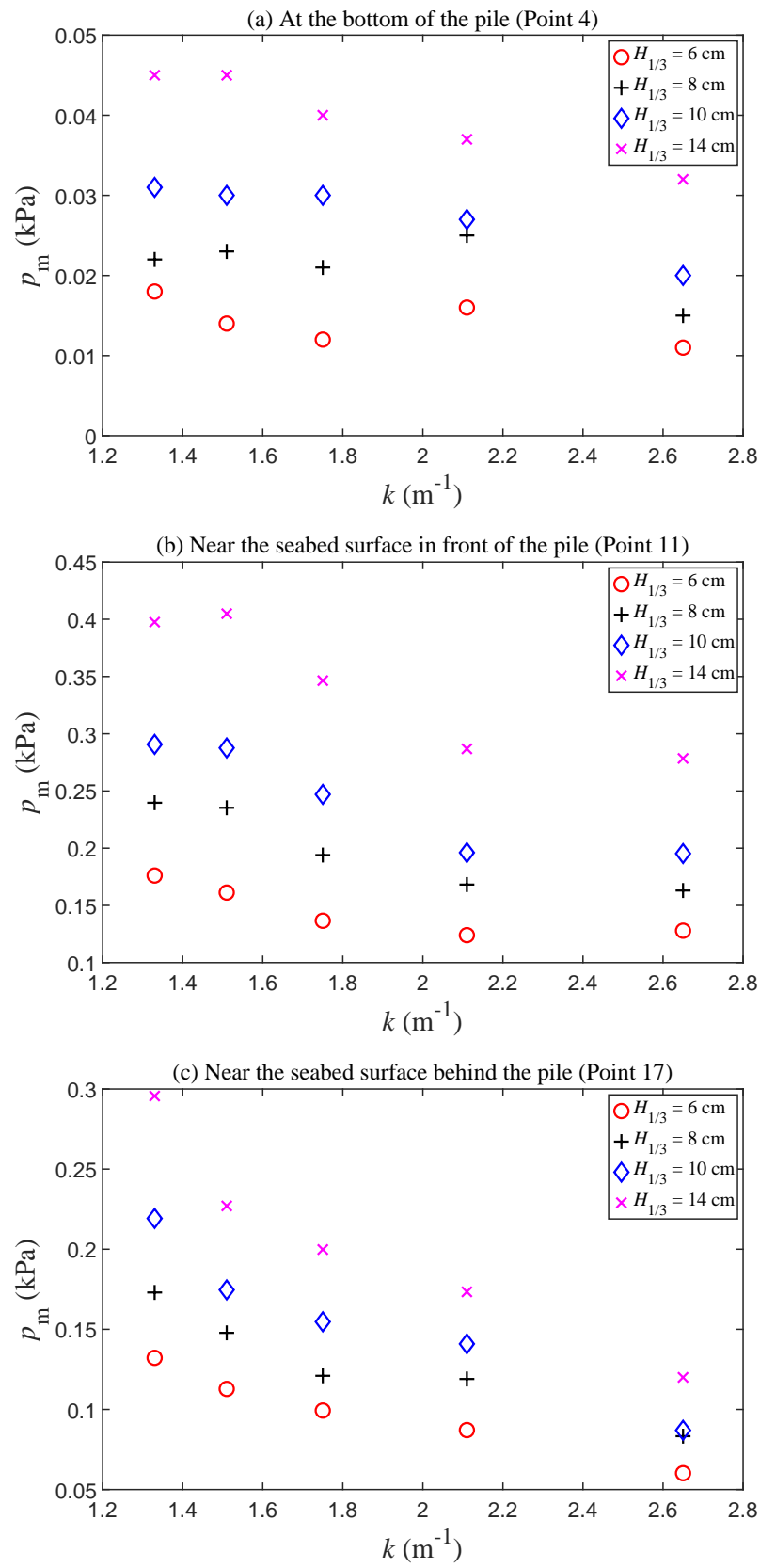

Figure 18: Distribution of the maximum pore-water pressures vs wave numbers for various wave heights at different Points $(x=0 \mathrm{~cm}, z=-0.6 \mathrm{~m}$, Point $4 ; x=15 \mathrm{~cm}, z=-0.05 \mathrm{~m}$, Point 11 and $x=-15 \mathrm{~cm}, z=-0.05 \mathrm{~m}$, Point 17). 
per and lower limits of pore-water pressure under the representative regular wave. From the figure, we can see the irregularity of irregular wave-induced pore-water pressure variation. In some specified moments, the pore pressure caused by irregular waves is larger than that of regular waves, which is caused by the randomness of wave heights. The instantaneous wave height exceeds the representative wave height of regular waves at some times, resulting in the consequence that maximum dynamic seabed response is much larger than that of regular waves. In addition, comparing the time series of pore pressures under different spectral irregular waves, it can also be found that the maximum pore pressure of various spectral irregular waves is quite different. Hence in practical engineering, the suitable wave spectrum should be selected according to the sea condition in order to ensure the safety.

Figure 20 further presents the effects of wave parameters on the maximum pore-water pressure along the depth direction of seabed. The irregular wave-induced seabed responses around the mono-pile are greater than that of the representative regular wave, but the distribution trends are similar. The maximum pore-water pressure decreases with the increase of the depth, which is consistent with the results of the semi-analytical solution proposed by Liu and Jeng [35]. Furthermore, as shown in the figure, the P-M type irregular wave-induced seabed response is the largest. The seabed responses of the other four types irregular waves are quite different near the seabed surface, but the difference is insignificant when the depth is large $(z / h<-$ $0.15)$.

\section{Conclusions}

Different from the existing experimental studies which focus on regular waves, an experimental study on irregular wave-induced seabed response around the mono-pile was carried out. Two series of tests were conducted in this study. First, the irregular wave was generated by JONSWAP spectrum, and a single pile was installed at a depth of $0.6 \mathrm{~m}$ below the seabed surface, whose top and bottom ends were fixed. The results of flume tests are presented, besides, the effects of wave parameters on seabed response and the distribution of pore-water pressure around the mono-pile are also analyzed. Second, the influence of various wave spectra on the wave-induced pore pressures in a sandy seabed is also investigated. Based on experimental data, the following conclusions can be drawn.

1. Due to the influence of the mono-pile, when the irregular wave propagates to the front side of the pile, the wave crest will increase, which 

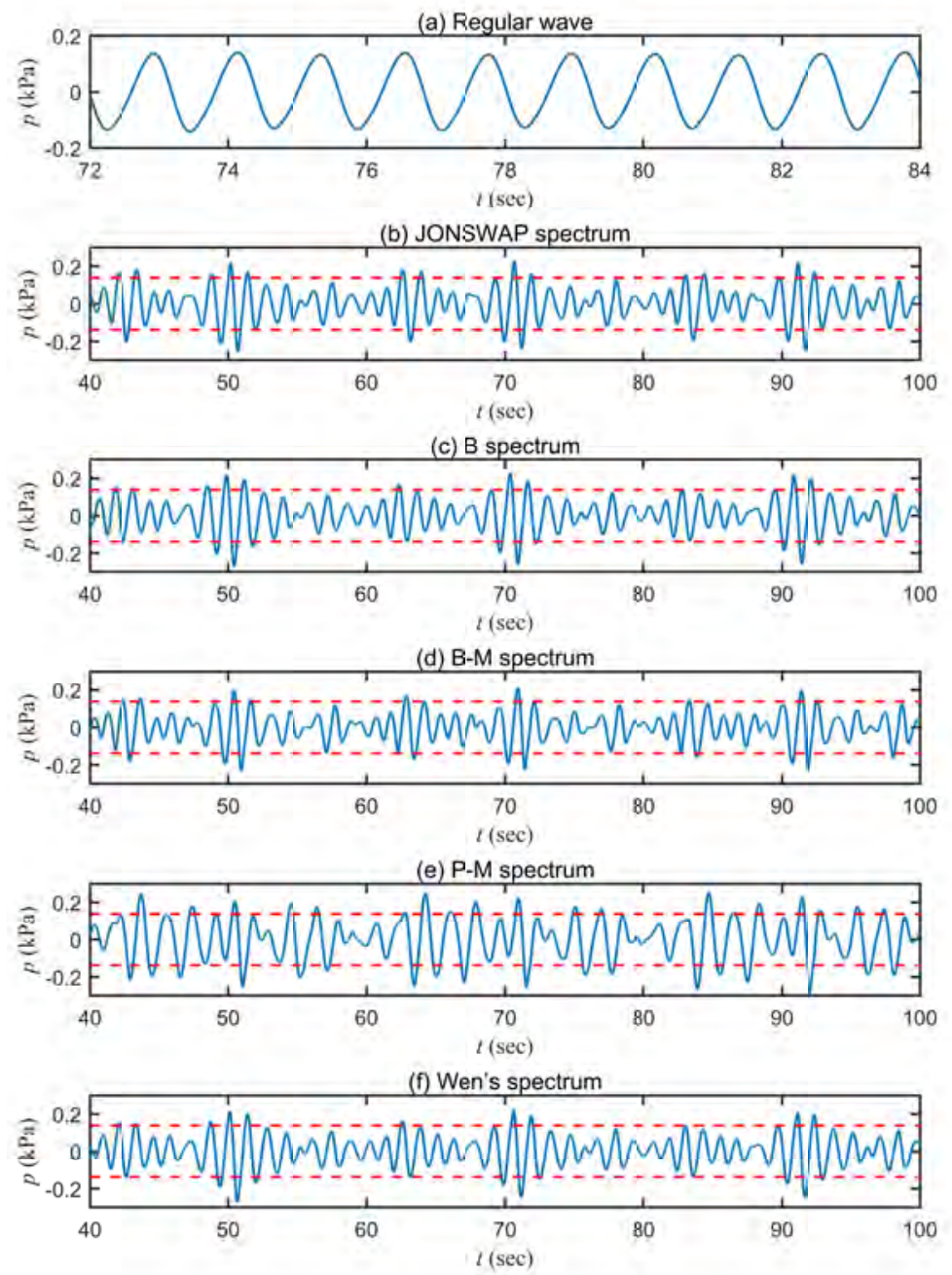

Figure 19: Distribution of pore-water pressures vs time with different wave spectra for Test 41 to $46\left(x=0.15 \mathrm{~m}, z=-0.15 \mathrm{~m}, H_{1 / 3}=10 \mathrm{~cm}, T_{1 / 3}=1.2 \mathrm{~s}\right.$, Point 11$)$. 


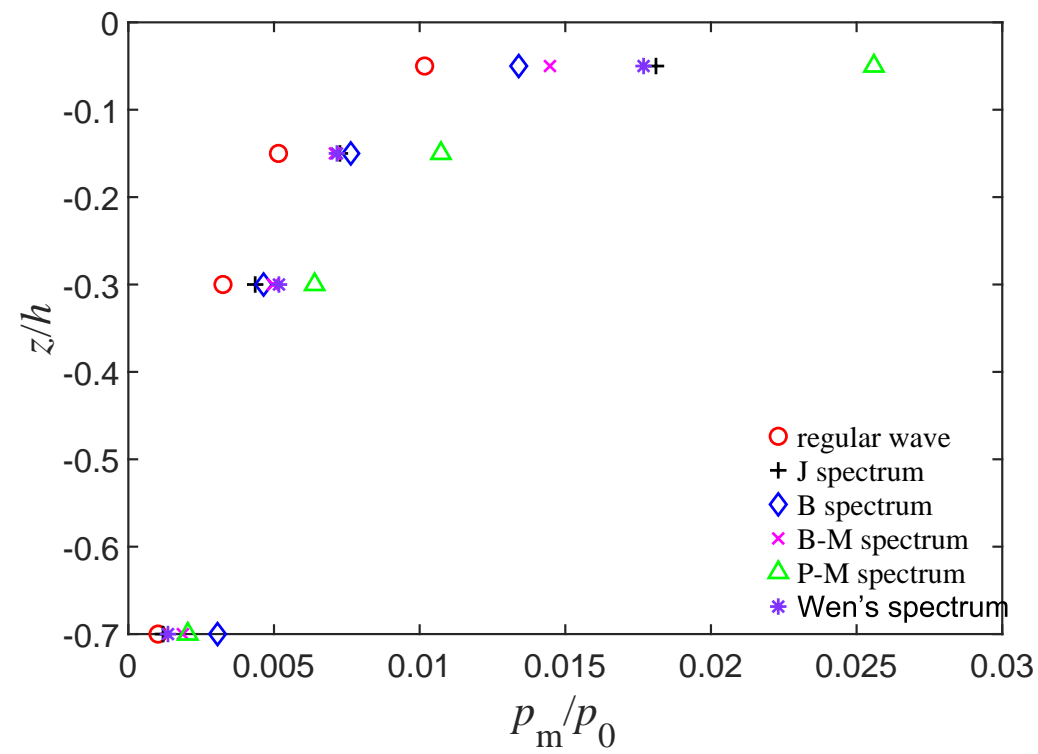

Figure 20: Distribution of the maximum pore-water pressure vs seabed depth $(z)$ along the back side of pile with different wave spectra for Test 41 to $46\left(x=-0.15 \mathrm{~m}, H_{1 / 3}=10\right.$ $\mathrm{cm}, T_{1 / 3}=1.2 \mathrm{~s}$, Point 17, 18, $19 \& 7$ ).

is caused by the interaction between incident wave and reflected wave. When waves pass through the pile, the diffraction will occur, which leads to the deformation of the wave profiles. This will have an impact on the response of seabed, resulting in the consequence that the pore-water pressure in front of the pile is larger than that behind the pile.

2. The seabed response caused by irregular waves shows obvious randomness. The pore-water pressure around the mono-pile increases as the increase of significant wave height and period, which is similar to the regular wave-induced seabed response.

3. With the increase of depth, the irregular wave-induced maximum porewater pressure decreases and the attenuation rate of pore-water pressure also decreases. In the region between the seabed surface and 0.3 $\mathrm{m}$ below it, this trend is significant. However, for the region below $0.3 \mathrm{~m}$, the seabed response is much smaller, and the influence of wave parameters is not obvious.

4. At the depth of $z=-0.15 \mathrm{~m}$, the maximum pore-water pressure caused by irregular waves occurs in front of the pile $\left(0^{\circ}\right)$, the minimum pore 
pressure occurs behind the pile $\left(180^{\circ}\right)$, and the pore-water pressure decreases from $0^{\circ}$ to $180^{\circ}$ along the circumferential direction of the pile. At the location beneath the pile $(z=-0.7 \mathrm{~m})$, the maximum pore pressure appears behind the pile $\left(180^{\circ}\right)$. Although the soil beneath the bottom of the pile is not directly affected by wave loading, the pore-water pressure can be transferred from the surrounding soil to it and still oscillate.

5. As a result to the irregularity of wave heights, the instantaneous wave height is larger than that of the representative regular wave at some moments, so the maximum seabed response under the action of irregular wave often exceeds the regular wave. However, the distribution trend of the maximum pore pressure along the depth direction of seabed is basically the same. Among various spectral irregular waves, the P-M type irregular wave-induced seabed response is the most intense, and the seabed responses under the other spectral irregular waves are significantly different only near the seabed surface $(z>-0.3$ $\mathrm{m})$.

\section{References}

[1] V. S. O. Kirca, B. M. Sumer, J. Fredsøe, Influence of clay content on wave-induced liquefaction, Journal of Waterway, Port, Coastal and Ocean Engineering, ASCE 140 (2014) 04014024.

[2] B. M. Sumer, Liquefaction around Marine Structures, World Scientific, New Jersey, 2014.

[3] D.-S. Jeng, Mechanics of wave-seabed-structure interactions: Modelling, processes and applications, Cambridge University Press, 2018.

[4] F. P. Gao, D.-S. Jeng, H. Sekiguchi, Numerical study on the interaction between non-linear wave, buried pipeline and non-homogeneous porous seabed, Computers and Geotechnics 30 (2003) 535-547.

[5] J.-S. Zhang, Y. Zhang, C. Zhang, D.-S. Jeng, Numerical modeling of seabed response to the combined wave-current loading, Journal of Offshore Mechanics and Arctic Engineering, ASME 135 (2013) 031102.

[6] J. Ye, D.-S. Jeng, Response of seabed to natural loading-waves and currents, Journal of Engineering Mechanics, ASCE 138 (2012) 601613. 
[7] M. A. Biot, General theory of three-dimensional consolidation, Journal of Applied Physics 26 (1941) 155-164.

[8] O. S. Madsen, Wave-induced pore pressures and effective stresses in a porous bed, Géotechnique 28 (1978) 377-393.

[9] T. Yamamoto, H. Koning, H. Sellmeijer, E. V. Hijum, On the response of a poro-elastic bed to water waves, Journal of Fluid Mechanics 87 (1978) 193-206.

[10] S. Okusa, Wave-induced stress in unsaturated submarine sediments, Géotechnique 35 (1985) 517-532.

[11] C. C. Mei, M. A. Foda, Wave-induced response in a fluid-filled poroelastic solid with a free surface-a boundary layer theory, Geophysical Journal of the Royal Astronomical Society 66 (1981) 597-631.

[12] X. Li, F. Gao, B. Yang, J. Zang, Wave-induced pore pressure response and soil liquefaction around pile foundation, International Journal of Offshore and Polar Engineering 21 (2011) 233-239.

[13] Z. Lin, D. Pokrajac, Y. Guo, D.-S. Jeng, T. Tang, N. Rey, J. Zheng, J. Zhang, Investigations of nonlinear wave-induced seabed response around mono-pile foundation, Coastal Engineering 121 (2017) 197-211.

[14] T. T. Sui, J. H. Zheng, C. Zhang, D.-S. Jeng, J.-S. Zhang, Y. Guo, R. He, Consolidation of unsaturated seabed around an inserted pile foundation and its effects on the wave-induced momentary liquefaction, Ocean Engineering 131 (2017) 308-321.

[15] R. Asumadu, J. S. Zhang, H. Y. Zhao, H. Osei-Wusuansa, A 3D numerical analysis of wave-induced seabed response around a monopile structure, Geomechanics and Geoengineering https://doi.org/10.1080/17486025.2019.1680882.

[16] J. F. A. Sleath, Wave-induced pressures in beds of sand, Journal of Hydraulics Division, ASCE 96 (1970) 367-378.

[17] F. P. Gao, X. Y. Gu, D.-S. Jeng, H. T. Teo, An experimental study for wave-induced instability of pipelines: The breakout of pipelines, Applied Ocean Research 24 (2002) 83-90.

[18] F. P. Gao, X. Y. Gu, D.-S. Jeng, Physical modelling of untrenched submarine pipeline instability, Ocean Engineering 30 (2003) 1283-1304. 
[19] D.-S. Jeng, C. Schacht, C. Lemckert, Experimental study on ocean waves propagating over a submerged breakwater in front of a vertical seawall, Ocean Engineering 32 (2005) 2231-2240.

[20] M. Kudella, H. Oumeraci, M. de Groot, P. Meijers, Large-scale experiments on pore pressure generation underneath a caisson breakwater., Journal of Waterways, Port, Coastal and Ocean Engineering, ASCE 132 (2006) 310-324.

[21] S. C. Chang, J. G. Lin, L. K. Chien, Y. F. Chiu, An experimental study on non-linear progressive wave-induced dynamic stresses in seabed, Ocean Engineering 34 (2007) 2311-2329.

[22] B. M. Sumer, V. S. O. Kirca, J. Fredsøe, Experimental validation of a mathematical model for seabed liquefaction under waves, International Journal of Offshore and Polar Engineering 22 (2012) 133-141.

[23] W. G. Qi, C. F. Li, D.-S. Jeng, F. P. Gao, Z. D. Liang, Combined wave-current induced excess pore-pressure in a sandy seabed: Flume observations and comparisons with analytical solution, Coastal Engineering 147 (2019) 89-98.

[24] K. Zen, H. Yamazaki, Mechanism of wave-induced liquefaction and densification in seabed, Soils and Foundations 30 (1990) 90-104.

[25] B. Chowdhury, G. R. Dasari, T. Nogami, Laboratory study of liquefaction due to wave-seabed interacton, Journal of Geotechnical and Geoenvironmental Engineering, ASCE 132 (2006) 841-851.

[26] B. Liu, D.-S. Jeng, G. L. Ye, B. Yang, Laboratory study for pore pressures in sandy deposit under wave loading, Ocean Engineering 106 (2015) 207-219.

[27] S. Sassa, H. Sekiguchi, Analysis of wave-induced liquefaction of sand beds, Géotechnique 51 (2001) 115-126.

[28] W. G. Qi, F. P. Gao, Physical modelling of local scour development around a large-diameter monopile in combined waves and current, Coastal Engineering 83 (2014) 72-81.

[29] S. Wang, P. Wang, H. Zhai, Q. Zhang, L. Chen, L. Duan, Y. Liu, D.S. Jeng, Experimental study for wave-induced pore-water pressures in a porous seabed around a mono-pile, Journal of Marine Science and Engineering 7 (2019) 237. 
[30] M. S. Longuet-Higgins, The statistical analysis of a random, moving surface, Philios Trans Royal Society 249 (1957) 321-387.

[31] K. Hasselmann, T. P. Barnett, E. Bouws, H. Carlson, D. E. Cartwright, K. Enke, J. A. Ewing, H. Gienapp, D. E. Hasselmann, P. Kruseman, A. Meerburg, P. Muller, D. J. Olbers, K. Richter, W. sell, H. Walden, Measurements of Wind-Wave Growth and Swell Decay during the Joint North Sea Wave Project (JONSWAP)., Technical Report 8, Erganzungsheft zur Deutschen Hydrographischen Zeitschrift Reihe A, 1973.

[32] N. Huang, S. Long, C. Tung, Y. Yuen, L. Bliven, A unified twoparameter wave spectral model for a general sea state, Journal of Fluid Mechanics 112 (1981) 203-224.

[33] S. C. Wen, D. C. Zhang, B. H. Cheng, P. F. Guo, Theoretical wind wave frequency spectra in deep water. I. form of spectrum, Acta Oceanology Sinca 7 (1988) 1-16.

[34] B. M. Sumer, J. Fredsøe, S. Christensen, M. L. Lind, Sinking/floatation of pipelines and other objects in liquefied soil under waves, Coastal Engineering 38 (1999) 53-90.

[35] H. Liu, D.-S. Jeng, A semi-analytical solution for random wave-induced soil response in marine sediments, Ocean Engineering 34 (2007) 12111224 .

[36] H. X. Xu, P. Dong, A probabilistic analysis of random wave-induced liquefaction., Ocean Engineering 38 (2011) 860-867.

[37] Y. Goda, Random seas and design of marine structures, World Scientific Press, 2000. 